\title{
A Study on the Relationship among Knowledge Acquisition Sources at the Teacher- and College-Level, Student Absorptive Capacity and Learning Outcomes: Using Student Prior Knowledge as a Moderator
}

\author{
Michael Yao-Ping Peng \\ Yango University
}

\author{
Zhaohua Zhang \\ Jinan University
}

Sophia Shi-Huei Ho
University of Taipei

\begin{abstract}
There are a multitude of factors influencing the learning outcomes of students, with all previous studies basing their conclusions upon predetermined variables according to different theories and exploring the relevance between them. In this study, two important antecedents - the transfer of teachers' knowledge and student orientation — are put forward based on the knowledge conversion theory and marketing concepts to explore the conspicuousness between various factors within the structural model. This study uses students from colleges in Taiwan as its research samples. Purposive sampling is adopted to acquire the samples required for statistics. A total of 801 participants are involved in this study. The results indicate that knowledge transfer at the teacher level plays a significant role in students' absorptive capacity and learning outcomes, that student orientation at college levels has a great influence on students' absorptive capacity, and that the prior knowledge of students has a positive moderating effect on the influence of teachers' knowledge transfer on students' absorptive capacities. Based on these results, the study provides suggestions for relevant theoretical and practical implications to indicate the contributions of this research.
\end{abstract}

\section{Keywords}

Teachers' Knowledge Transfer $\bullet$ Student Orientation $\bullet$ Absorptive Capacity $\bullet$ Learning Outcome $\bullet$ Prior Knowledge

Correspondence to Zhaohua Zhang, Associate Professor, School of Humanities, Jinan University, China. Email: tzngg@ jnu.edu.cn 
Since Peter Durak, the Master of Management, proposed the term "knowledge economy" more than a decade ago, its connotation and essence have begun to deepen within the economic, social, political, military, industrial, and most importantly education, fields; that is, the importance of knowledge. In the industry, knowledge workers play an important role, and their knowledge conservation replaces factors of production from the economics in the past, such as labor or capital (Drucker, 1999). However, knowledge workers know that the development of education depends largely on higher education, because higher education will provide students with any element needed to become knowledge workers, including curriculum teaching, learning guidance, learning environment (Ding, Wei, \& Mollohan, 2016). In most of the past studies, the influence of knowledge on the development of individual ability was discussed from the view of industry or human resources management (Cho, Eum, \& Lee, 2013; Cho \& Korte, 2014). However, few studies have mentioned how higher education institutions should transfer knowledge to the student community (Kibbe, 2015; Tho, 2017). Therefore, this study uses students of higher education institutions as research subjects to explore the correlation between student knowledge acquisition and ability accumulation, as one of its research aims.

In the context of knowledge management, knowledge is formed by the pattern of data $\rightarrow$ information $\rightarrow$ knowledge. This means that not all received information or information can be used by an individual (Kibbe, 2015). Through a series of transformation processes, valuable and proprietary knowledge can be produced (Dalkir \& Beaulieu, 2017). The knowledge conversion theory provides knowledge of the theoretical basis of interpretation, focusing on the mutual effect between tacit and explicit knowledge (Hau, Kim, Lee, \& Kim, 2013; Nonaka \& Takeuchi, 1995). The prerequisite is that the conversion of valuable knowledge must be based on common prior knowledge between individuals. Therefore, if the heterogeneity between individuals is typically high, the knowledge conversion process will fail. Most studies use the knowledge transfer stage proposed by Nonaka and Takeuch (1995) to discuss the impact of knowledge transfer on the ability and performance within or between enterprises; however, few studies have applied the knowledge conversion theory to higher education (Tho, 2017). Its research framework conducts empirical analysis. In higher education, the preexisting qualities of students are mostly homogeneous, and the curriculum and teaching provided by teachers belong to the transmission of knowledge category. Therefore, the adoption of knowledge conversion theory in the cultivation of the ability of college students, and thus how to obtain better student learning outcomes is the second aim for this study.

In addition to teachers' knowledge transfer, their teaching model and style also determine whether or not the student truly acquires the required knowledge and ability from the learning process. In the past, the teaching model could be divided into teacher-centered concepts and student orientation (Struyven, Dochy, \& Janssens, 2010; Murphy \& Rodríguez-Manzanares, 2009). These two distinct teaching models will result in students having different learning development and competence orientation (Kibbe, 2015; Sturm \& Bogner, 2008). At the teacher-centered level, teachers are in charge of the entire learning process. Most of the students' time is devoted to explanations from teachers on the podium (Murphy \& RodríguezManzanares, 2009). Student consistency materials are also provided. It is apparent it is more biased towards a mechanical learning model. At the student orientation level, teachers shift the pedagogical dominance to students, guiding students to speak at a higher frequency; not only from a single textbook, but in a more meta-cooperative learning model (Struyven et al., 2010; Sturm \& Bogner, 2008). The design of the learning environment can be regarded as a highly student-oriented learning model. In a multi-interactive and interactive learning environment, it can be regarded as a source of important knowledge, although scholars believe that an open learning environment can help students develop superior capabilities and achieve better learning outcomes (Kertechian, 2018; Pesch, Calhoun, Schneider, \& Bristow, 2008; Struyven et al., 2010). 
However, few empirical studies provide a comprehensive and integrated framework to verify the importance of student orientation. Therefore, student orientation is added to the pre-variables of the study's framework to understand the correlation between student orientation, ability and learning outcomes.

Although students can attain valuable knowledge and information from teachers and an open learning environment, they cannot be sure that they can develop high-quality skills. Although the theory of knowledge transfer indicates that individuals systematically integrate and internalize information and turn it into knowledge, this point seems to ignore how students use this valuable know-how, and whether students can successfully internalize such knowledge and in turn develop their own capabilities (Tho, 2017). In organizational management research, Zaheer and Bell (2005) combined a resource-based viewpoint and network theory. They believe that in exploring external organizational knowledge and information, attention should be paid to the organizational internal capacity to absorb knowledge, meaning absorptive capacity (Tho, 2017). As Fabrizio (2009) attaches importance to connectedness, students are supposed to have some methods and mechanisms to learn, digest, transfer and apply know-how, thus strengthening the benefits of knowledge. Studies in the past in the area of education have seldom addressed relevant issues such as student self-absorption and digesting knowledge (Cho et al., 2013; Cho \& Korte, 2014). Even with rich and valuable knowledge and information, it is necessary to consider the absorptive capacity of students. Therefore, this study regards absorptive capacity as an intermediate variable demonstrating importance between knowledge acquisition and learning outcomes, as the third aim of this study.

According to the above explanations, this study intends to propose relevant research contributions based on the following theoretical gaps: (i) applying knowledge transfer theory to higher education, and exploring the effectiveness of teachers' knowledge transfer; (ii) exploring the level of absorptive capacity from the perspective of students to cultivate and establish student ability and effectiveness, and verify the relevance between the two; (iii) add the concept of marketing to student learning to discuss the relevance between student orientation and learning absorptive capacity and learning outcomes.

\section{Student absorptive capacity}

\section{Literature review and hypotheses development}

The concept of absorptive capacity proposed by Cohen and Levinthal (1990, p. 129) was defined as the ability of enterprises "to identify new values, obtain external knowledge, digest and absorb and apply this knowledge to commercial purposes". According to Nieto and Quevedo's (2005) research, they combined the absorptive capacity definition of Cohen and Levinthal (1990), and Fiol and Marjorie (1985) and developed four dimensions as the measurements of absorptive capacity, namely, communication with the external environment, the diversity and overlap of knowledge level and experience within an organization, knowledge structure and strategic positioning. Therefore, when an organization is able to absorb new knowledge and transform it into products, processes or systems, the organization has excellent absorptive capacity. Absorptive capacity develops new knowledge and promotes its transfer by utilizing existing knowledge. In other words, under circumstance of higher education, the accumulation of students' own abilities will determine how to apply, integrate and even develop their core competencies. Cadiz, Sawyer, and Griffith (2009) pointed out that the individual's absorptive capacity is a process through which new knowledge is assessed (valuation and screening of valuable information), assimilated (converting new knowledge into helpful knowledge), and applied (using knowledge). Having a strong absorptive capacity will allow students to generate new ideas in the process of learning and even lead to considerable advancements in the efficiency of knowledge transfer during teamwork to complete tasks assigned by teachers (Wang \& Ahmed, 2007). The absorption and the role of knowledge in a student's internal 
assimilation process are quite abstract and more subtle, which is the reason why absorptive capacity measurement is quite complicated and not yet universally defined. Zahra and George (2002) argue that absorptive capacity is acquired through knowledge acquirement, knowledge assimilation, transmission and utilization.

The components of employability include knowledge, skills and various abilities (Hennemann \& Liefner, 2010). In the learning context of higher education, if the ability to absorb knowledge is not equipped with at the receiving end of the knowledge, students may not be able to effectively use this knowledge, even if the teacher or college partially transmits valuable knowledge. Students with a sufficient degree of absorptive capacity will retain valuable knowledge, and openly communicate and exchange knowledge on the basis of common language and interest (Cadiz et al., 2009). As such, it will have a positive effect on employability. A study by Nor, Nor, Daud, and Kamaruddin (2012) pointed out that students with absorptive capacity have superior prior knowledge and academic achievement. They can effectively transfer knowledge, apply knowledge, and use it to improve their future academic works and achievements, thereby enhancing employability. Considering the above, this study raises the hypotheses as follows:

\section{H1: Student absorptive capacity has a positive association with student learning outcomes.}

\section{Teacher knowledge transfer}

According to the perspective of cognitive learning, students can use their own abilities and resources to establish their own core competencies and use their abilities to shape their employability. Whether it is the acquisition, accumulation or the creation of knowledge, it is bound to be influenced by the knowledge transfer process. Only through knowledge transfer we can effectively create new knowledge to apply to management processes and create value for individuals (Khamseh \& Jolly, 2008). However, when students lack the necessary knowledge, this process occurs externally via the teacher's teaching or learning mode. As Machlup (1962) believes, knowledge transfer is a process of knowledge acquisition by knowledge receivers. As knowledge providers have acquired knowledge, and knowledge receivers may not yet have this knowledge, it breaks down as a process of knowledge acquisition by knowledge receivers (knowing) (Von Krogh \& Roos, 1994). Therefore, while seeking knowledge from knowledge receivers, it is required to internalize the received information through the learning process. Knowledge exists in human minds through learning or experience, and then gradually grows with experience. It involves personal beliefs, judgments and value recognition. It is implicit in addition to explicit written actions. Polanyi (1962) distinguishes tacit knowledge from explicit knowledge. Tacit knowledge means knowledge is non-verbal, intuitive and cannot be specified in detail. However, the differences between tacit and explicit knowledge are not supposed to be considered as a dichotomy, but as a continuous band (Nonaka \& von Krogh, 2009), from explicit knowledge presented in specific products and processes to being embodied within personal cognition and organizational routines as tacit knowledge acquired from experience and use (Zhou, Siu, \& Wang, 2010). According to the above description, this study defines teachers' knowledge transfer as a learning process in which teachers will transfer tacit and explicit knowledge to students through knowledge externalization and enable students to combine this with their existing knowledge.

Teachers' knowledge transfer helps students to learn richer knowledge content. In addition to the teaching experience of teachers, it also needs the cooperation of its learning environment. As mentioned above, knowledge transfer is a learning process and involves learning in this process, facing changes in the environment, the assignment of course tasks and the conversion of teaching styles. According to the traits of knowledge transfer, although it is more difficult to transfer tacit knowledge than explicit knowledge, teachers learn the value of knowledge through a learning model. The use of explicit knowledge is helpful to 
enhance general and professional work competency, and the in-house knowledge of teachers can promote the improvement of learning efficiency and effectiveness, thereby improving students' work attitude and self-confidence. In both general and professional capacities, explicit knowledge plays an indispensable role, but the most important of these is the mutual integration of tacit knowledge to enhance the kinetic energy of innovation. In addition, Teigland and Wasko (2009) believe that explicit knowledge transfer will help the re-use of know-how among students, in addition to solving common problems, interaction with teachers and facilitating new know-how. The transfer and integration of tacit know-how can create new ideas as well as novel solutions. Therefore, this study infers the following hypotheses:

H2: Teachers' knowledge transfer is positively associated with student learning outcomes.

H3: Teachers' knowledge transfer is positively associated with student absorptive capacity.

\section{Student orientation model}

In marketing literature, the issue of "why we want to make the organization more customeroriented" is widely met and related to superior organizational performance. This kind of customer orientation is similar to the concept of marketing proposed by Deshpande and Webster as beening "the unique culture of an organization, which enables the organization to think about the direction of strategy and operations centered on the customer" (Deshpande \& Webster, 1989, p. 4). According to Schein (1992, p. 12), the organizational culture is defined as "a set of basic assumptions that are discovered, invented, or developed by specific ethnic groups". They learn to handle issues about internal integration and external adaptation of the organization, and are taught to newcomers and correct their perceptions, thoughts and feelings. Many scholars have also confirmed from research results that they can fully understand the target customers, predict customer needs and continue to create excellence for them (Narver \& Slater, 1990).

However, few studies or practices have used customer-oriented strategies in higher education, but in the past the essence of higher education was to nurture social elites. Only students who entered university studies could create self-worth and create social class reversals. Higher education institutions have good reputation and student sources, even if they are not marketing-oriented. However, under the circumstances of the establishment of higher education institutions, this educational environment has changed from elite education to mass education. Many colleges also begin to attend marketing activities for survival, formulating marketing strategies to attract students.

Many higher education institutions in the United States began to discuss brand value, brand equity and establish long-term brand trust from a marketing perspective in 2001. According to the University of Cincinnati (UC) in 2001, the university's brand "is based on its own brand essence, brand character and brand attributes, creating a point of variation among competing universities" (Pesch et al., 2008, p. 100). In 2002, the University of Hawaii System expanded its brand strategy team to establish the brand positioning of the University of Hawaii System. These signs mean that many higher education institutions are aware that they are facing a fiercely competitive and constantly changing context, and such a context provides them with opportunities from all over the world to win over outstanding students. In the California system, 130 higher education institutions are dedicated to attracting and retaining students. It can be seen that higher education institutions in Europe and the United States have begun to look at the relationship between universities and students from the view of marketing exchange to establish competitive advantages (Amyx, Bristow, \& Luehlfing, 2005; Bristow \& Amyx, 2006). University faculty members began to apply marketing concepts to academic units and recognized the importance of adopting customer orientation. This concept not only means that the university only meets the needs of students but provides students with high-quality educational experience regardless of cost and regards students as important customers, and then proposes 
the concept of student orientation. Therefore, based on past marketing literature and higher education development, this study defines student orientation as higher education institutions construct a customeroriented culture with the concept of marketing, and meet the educational needs and experience of students as an important task that should be implemented to enhance student loyalty.

As mentioned above, student orientation implies that the higher education institution adopts the marketing concept of customer orientation. Its essence lies in the establishment of an internal marketing culture that treats students as their customers to meet their needs and thus create student values. However, the establishment of college culture and maintenance is not as easy as simply amending the articles of incorporation, but rather must follow the development of the timeline and be structured from the top down. When the higher education institutions have a high student orientation, the staff of the institutions can provide students with exclusive service contact experience, so that the students can feel the intentions and efforts of the institution and reduce the possibility of dropping out of college. The goal is academic success and academic achievement, allowing institutions to increase their chances of retaining students (Pesch et al., 2008). Scholars believe that higher education institutions with student orientation can help students to adjust their interests and needs in an optimal and rational manner (Olssen \& Peters, 2007). In order to provide a friendly educational experience, institutions consider students as professional output - customers to listen to in meeting their needs and desires as students (Desai, Damewood, \& Jones, 2001). When institutions can deliver the educational experience and learning needs that students require, students will feel that the institution's commitment to meeting learning needs (Pesch et al., 2008) will be reflected in students' learning outcomes and quality improvement. In addition, students are more likely to accept the guidance of teachers, to engage in the study of knowledge and skills, and to enhance the effectiveness of teaching (Koris \& Nokelainen, 2015). In summary, this study proposes the following hypotheses:

H4: The student orientation pattern has a positive association with the student learning outcome.

H5: The student orientation pattern has a positive association with student absorptive capacity.

\section{Moderating effect of students' prior knowledge}

The interpretation of status and information depends on self-perception. Self-perception can distinguish things and their environment (Roth, 2006). In other words, self-perception can be used to help learners learn, but learners do not necessarily understand self-perception. In fact, the use of self-perception is related to the establishment and the learner's own past experience, as most cognitive strategies rely on prior knowledge. The understanding of curriculum knowledge and information is no exception (Mathai \& Ramadas, 2009). The function of prior knowledge is to help learners to understand external knowledge and information and combine their knowledge content with the learner's own prior knowledge to generate a richer basis of prior knowledge. Therefore, prior knowledge is not always the same, but has the characteristic of path dependence, growing with time, and it depends on learners' learning attitude and learning motivation to strengthen their own prior knowledge. Simcock and DeLoache (2006), from the perspective of graphic interpretation, explore the hierarchy of objects' need for graphic capabilities - including perception, interpretation and an understanding of the nature of graphics and the ability to use them - and that domainspecific knowledge will affect the selection and coding of messages from complex graphics and from interpreted and inferred translated messages (Canham \& Hegarty, 2010). In summary, prior knowledge can be defined as the knowledge base students have before absorbing knowledge, allowing students to perceive, interpret, code, and interpret external knowledge to face the uncertainty of the environment.

In the study of students' prior knowledge, scholars discuss the effects of prior knowledge on

different theoretical bases. Although some empirical studies point out that prior knowledge does not have 
any consequence on the learner's learning performance (Mishra \& Yadav, 2006; Müller-Kalthoff \& Möller, 2003), there are still many scholars who believe that prior knowledge has significant relevance to learning. Amadieu, Tricot, and Mariné (2009) used the Cognitive Load Theory to study the effect of learners' prior knowledge on learning electronic documents. They believe that learners with more prior knowledge can process information and organize themselves with their own mental models. In addition, learners with more prior knowledge will be less prone to learning puzzles than low-level learners (Jenkins, Fuchs, Van Den Broek, Espin, \& Deno 2003; Mishra \& Yadav, 2006), but studies have also found that they are confusing and subjective, with no significant support (Müller-Kalthoff \& Möller, 2003). The most probable factor is that learners may have limited prior knowledge of explicit and written knowledge, even if they have more prior knowledge. Nevertheless, learners with more prior knowledge will be more knowledgeable about tacit and complex knowledge and information. Careful and deep exploration of knowledge content (Jenkins et al., 2003) may help translate these inquiry processes into their own absorptive capacity. In summary, this study deduces the following hypothesis:

H6: Students' prior knowledge will interfere with the relationship between teacher's knowledge transfer and absorptive capacity.

\section{Research framework}

This study intends to explore the learning process of students' knowledge learning, absorption and effectiveness manifested from the perspective of knowledge transfer, and joins with the concept of marketing, proposing student orientation as an incentive for students to learn.

To more clearly demonstrate the hypothesis mentioned above in current study, the following research framework will show the relevance among knowledge transfer, student orientation, student absorptive capacity, prior knowledge, and learning outcome. Furthermore, the direct path is analyzed by structural equation model (SEM), while the effect of the moderating variable is analyzed by the hierarchical regression. Figure 1 shows the research framework.

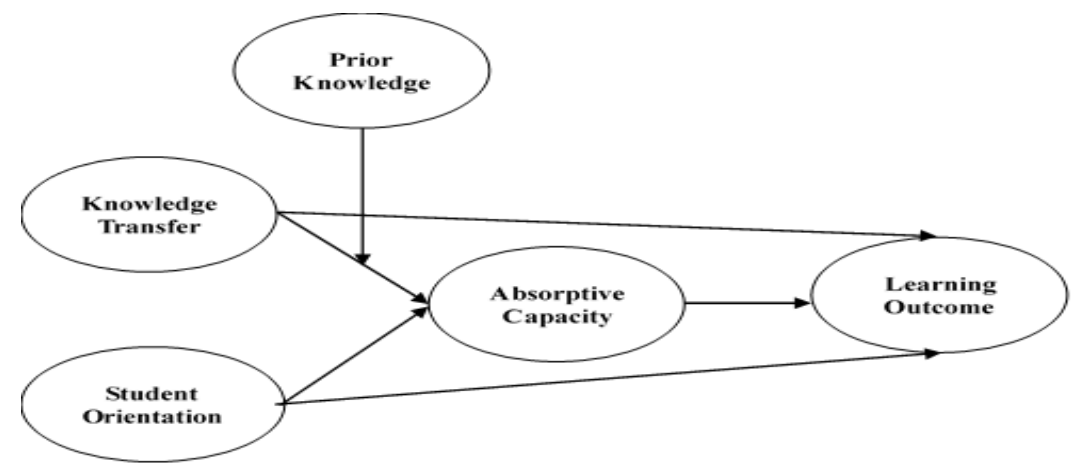

Figure 1. Research framework

\section{Participants}

Method

Before the sampling of students, this study considered different college characteristics, such as geographic location, college size, college category, and college attributes, so as to increase the general level of research and adopt a method of intentional sampling. Of the sampled universities, there are a total of 7 state colleges and 9 private colleges, with the students of the Department of Social Sciences and the 
Department of Natural Sciences of these colleges the ones being surveyed. There were 822 participants in total. After the questionnaires were checked, 21 of them were invalidated, with 801 valid ones left. There are $46.8 \%$ male students and $53.2 \%$ female students, was representative by gender; $33.4 \%$ are sophomore students, $35.6 \%$ are junior students, and $31 \%$ are senior students, was representative by degree. Fifty-sevenpoint five percent of students are studying social sciences, and $42.5 \%$ of students are studying natural sciences, was representative by major. Moreover, most students (53.8\%) spent less than five hours on selfstudy each week, and 30.4\% of them 6-10 hours, was representative by academic involvement. Thirty-sixpoint five percentage of students are First-generation college students.

\section{Instruments}

The student learning outcome can be divided into two levels: cognitive gains and non-cognitive gains. This study uses the Cognitive Benefit Scale proposed by Pike, Kuh, McCormick, Ethington, and Smart (2011) that contains nine items. Respondents were asked to point out the degree of progress in the learning experience of the college, covering general education, quantitative analysis, critical thinking and writing and oral expression. Non-cognitive benefit was derived from the subject's self-understanding and teamwork. There is a total of 7 items on assignments, development of ethical standards and responses and perceptions of citizen/community participation. Cronbach's alpha of cognitive gains and non-cognitive gains were .87 and .85 , indicating sufficient internal consistency.

In the Absorptive Capacity section, with a purpose of understanding the student's understanding of the absorptive capacity, this study defines absorptive capacity as using new knowledge through assessment (identification and screening of valuable information) and digestion (converting new knowledge into helpful knowledge). Furthermore, the process of applying (using knowledge) translates into usable knowledge. The questionnaire used the scale designed by Cadiz, Sawyer, and Griffith (2009), which includes Assimilation (3 questions), Application (3 questions), and Assessment (3 questions). Items such as "I can explain the most valuable knowledge to me"; "Students will share knowledge, making it easy for us to understand the knowledge in our professional field"; "My studies enable me to quickly apply new technical knowledge", etc. Cronbach's alpha of assessment, assimilation and application were .86, .81 and .87, indicating sufficient internal consistency.

Teachers' knowledge transfer uses the Explicit knowledge (5 questions) and Tacit knowledge (4 questions) scales developed by Zhou et al. (2010), in which Explicit knowledge measures all knowledge that occurs in the classroom, including reports, methods and materials, such as: teachers can specify course requirements and teaching content, and Tacit knowledge includes the sharing of experience, opinions and personal history, such as how teachers will discuss with students when performing tasks. Cronbach's alpha of explicit knowledge and tacit knowledge were .92 and .81 .

The Student Orientation Scale is a scale designed by Pesch et al. (2008). There are seven items that require the students to state any supportive feelings and perceptions of the colleges. "The administrators in such colleges are willing to help students to achieve their goals"; "The college will consider the demands of the students"; "The college believes that the students are important" and so on. Cronbach's alpha was .95.

Student Prior Knowledge uses 10 important skills developed by Silva, Lourtie, and Aires (2013) to require students to assess their current level of knowledge, including self-awareness, planning, critical analysis, decision-making ability, problem solving, self-management ability, awareness of globalization, understanding of applied disciplines, willingness to learn, and teamwork. Cronbach's alpha was .93. The Likert 7-point scale was used to measure all subjects, and the results show that 1 of them is very disagreeable and 7 of them are very agreeable. 


\section{Design and procedure}

This is a cross-sectional study whose research framework and survey instrument have been approved by Institutional Review Board of University of Taipei. The researchers contacted with the colleges and teachers who were willing to receive the questionnaire by telephone and email first. The survey packages were sent by post to students of 16 higher education institutions. Each survey package contained a covering letter explaining the survey purpose, a survey instrument and a postage-paid envelope. Before filling out the questionnaires, students have been asked to understand the right of attending survey to ensure research ethical aspects.

\section{Data analysis}

Before validating the path relationships, this study first examined the validity and reliability of the models and variables to confirm the interpretability of the models. All variables were higher than 0.7 . The table shows that this study scale has a high degree of internal consistency. Another measure of validity is divided into two categories: "convergence validity" and "discriminate validity" (Hair, Black, Babin, \& Anderson, 2010). This study uses confirmatory factor analysis (CFA) to perform tests and refers to Fornell and Larcker (1981) criteria for the evaluation of convergence validity: (i) all standardized loading should be greater than 0.5 and reach the level of significance, (ii) The composite reliability (CR) must be greater than 0.7, and (iii) the average variation. In Table 1, average variance extracted (AVE) is greater than 0.5. The AVEs of each facet of the study were between 0.54 and 0.72 , CR values were in a range from 0.8 to 0.95 , and the fits of the variables were all in good order. This indicates that the variables of the study model have good convergence validity.

In this study, reference was made to Capron (1999) criteria for assessing discriminant validity; i.e., the existence of discriminant validity was supported when the root-opening value of the average variation extraction was greater than the absolute value of the facet correlation coefficient. The findings of the study show that the root number of the average variation extraction is larger than the absolute value of other coefficients in the column of the correlation coefficient table. As such, the study has discriminant validity.

Table 1. Analysis of reliability and validity

\begin{tabular}{|c|c|c|c|c|c|c|c|c|c|}
\hline & 1 & 2 & 3 & 4 & 5 & 6 & 7 & 8 & 9 \\
\hline 1. Cognitive gains & .74 & & & & & & & & \\
\hline 2. Non-cognitive gains & $.701^{* *}$ & .75 & & & & & & & \\
\hline 3. Assessment & .027 & -.009 & .82 & & & & & & \\
\hline 4. Assimilation & -.007 & -.021 & $.704^{* *}$ & .76 & & & & & \\
\hline 5. Application & .012 & .004 & $.713^{* *}$ & $.731^{* * *}$ & .83 & & & & \\
\hline 6. Tacit knowledge & .060 & .043 & $.446^{* *}$ & $.506^{* * *}$ & $.491^{* *}$ & .85 & & & \\
\hline 7. Explicit knowledge & .039 & .016 & $.422^{* *}$ & $.483^{* * *}$ & $.449^{* *}$ & $.835^{* *}$ & .84 & & \\
\hline 8. Student orientation & -.022 & -.037 & $.475^{* *}$ & $.372^{* *}$ & $.419^{* *}$ & $.510^{* * *}$ & $.552^{* * *}$ & .84 & \\
\hline 9. Prior knowledge & .013 & -.023 & $.649^{* *}$ & $.576^{* *}$ & $.604^{* *}$ & $.397^{* *}$ & $.409^{* *}$ & $.467^{* *}$ & .76 \\
\hline Mean & 3.46 & 3.65 & 3.57 & 3.77 & 3.68 & 3.93 & 3.90 & 3.42 & 3.43 \\
\hline$S D$ & 0.57 & 0.63 & 0.68 & 0.65 & 0.69 & 0.67 & 0.67 & 0.77 & 0.67 \\
\hline$A$ & .87 & .85 & .86 & .81 & .87 & .91 & .92 & .95 & .93 \\
\hline AVE & .54 & .56 & .67 & .58 & .69 & .72 & .71 & .71 & .58 \\
\hline $\mathrm{CR}$ & .86 & .85 & .86 & .80 & .87 & .91 & .92 & .95 & .93 \\
\hline
\end{tabular}

$* * p<.01$

Note. In boldfaced, the square root of AVE. $S D=$ Standard Deviation; AVE = Average Variance Extracted; CR = Composite Reliability 


\section{An examination of the structural model}

\section{Results}

In this study, the measurement patterns of the above-mentioned potential variables are established according to the research framework, and the model matching degree of the structural equation modeling (SEM) verification theory is adopted. For mode matching tests, Bagozzi and Yi (1988) considered that the size of the sample should be considered and suggested that when the mode fit is measured by the ratio of $\chi^{2}$ to the degree of freedom $(d f)$, it generally does not exceed three (Hair et al., 2010). In this study, 801 valid questionnaires were analyzed. The results are shown in Table 2 . The ratio of $\chi^{2}$ to its $d f$ is less than 3 ; parsimonious normed fit index (PNFI) is greater than 0.5; goodness of fit index (GFI), adjusted goodness of fit index (AGFI), normed fit index (NFI), comparative fit index (CFI), and incremental fit index (IFI) are all greater than 0.9; root mean square error of approximation (RMSEA) is less than 0.08 (Jöreskog \& Sörbom, 1993). The moderation of this research model is acceptable.

\section{Table 2. Fit indices of structural model}

\begin{tabular}{cccc}
\hline Fit indices & Criteria & Findings & Results \\
\hline$\chi^{2} / \mathrm{df}$ & $<3.00$ & 2.890 & Confirmed \\
\hline GFI & $>0.9$ & 0.969 & Confirmed \\
\hline AGFI & $>0.9$ & 0.950 & Confirmed \\
\hline RMSEA & $<0.08$ & 0.049 & Confirmed \\
\hline NFI & $>0.9$ & 0.979 & Confirmed \\
\hline CFI & $>0.9$ & 0.986 & Confirmed \\
\hline IFI & $>0.9$ & 0.986 & Confirmed \\
\hline PNFI & $>0.5$ & 0.699 & Confirmed
\end{tabular}

\section{Verification of Structural Model}

In this study, the correlation among variables was detected using SEM in the model. There are many items in the consideration of certain facet scales. If a single question is used as the observation index for analysis, the model will become complicated and the number of samples required for analysis will also be relatively small. Inflated, coupled with the fact that some topics may deviate significantly from normal distribution, resulting in low fitness, so the study used item parcelling for SEM (Little, Cunningham, \& Shahar, 2002). That is to say, in the research topic items, the ones with the highest loads are combined with the ones with the lowest loads, and the ones with the second highest is combined with the ones with the second lowest, and so on.

The findings of this study are shown in Figure 2. The path coefficient of student absorptive capacity for student learning outcomes is - .03 ( $p>.10)$. H1 is false. Furthermore, the path coefficient of the Teacher's knowledge transfer to the Student learning outcome is $0.12(p<.10)$. H2 is supported. The higher the depth and breadth of the teacher's knowledge transfer, the more effective the student's learning can be. Similarly, the path coefficient of teachers' knowledge transfer to student absorptive capacity was $0.47(p<.001)$. Hypothesis $\mathrm{H} 3$ also received support, indicating that the content of teachers' knowledge transfer has become more mature, as with the student's own ability to absorb and apply knowledge.

In addition, the path coefficient of student orientation for the student learning outcomes is - .09 ( $p$ $>$.10), indicating that if the college constructs the student orientation culture, it will be difficult to improve 
upon the student's learning outcome. Therefore, H4 has not been supported. However, the path coefficient of student orientation to student absorptive capacity was .22 $(p<.001)$, indicating that the college continued to strengthen the marketing concept of student orientation, which will enhance students' ability to absorb and apply knowledge. H5 proves to be true.

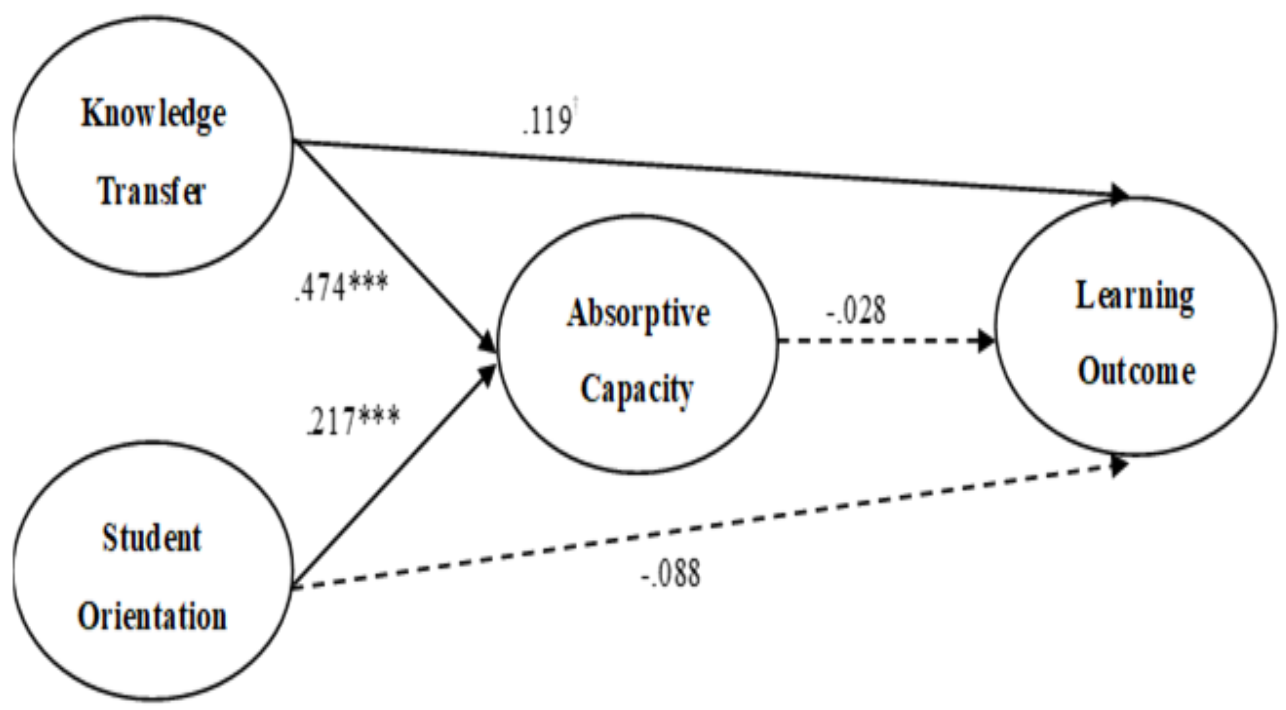

$\dagger$ if $p<.01 ; * * *$ if $p<.001$

Figure 2. Standardized path coefficient of the structural model

\section{Testing of Moderating Effect}

In the subsequent hypothesis testing, this study added relevant control variables (gender, subject, college attributes and college category). This section uses absorptive capacity as an imaginary variable, and teachers' knowledge transfer and the prior knowledge of students as an independent variable to perform hierarchical regression analysis. Since the setting of the moderating variable is due to the multiplication of student absorptive capacity and the student's prior knowledge, the collinearity problem may arise between the variables before the regression analysis. Therefore, Aiken and West (1991) proposed to increase the number of crossings. Before the item, the relevant variables were deflated and the reduced data was added to the moderating item of teachers' knowledge transfer and the student's prior knowledge to avoid collinearity.

In the regression model, the moderating effect of prior knowledge was added to the influence of teacher's knowledge transfer on student absorptive capacity. Table 3 shows a significant interaction between teachers' knowledge transfer and student absorptive capacity $(\beta=.069 *)$, so H6 is supported. The increase in coefficient strength of Model 4 and Model 3 may be due to the increased variation in explanatory variables after the addition of moderating variables. 
Table 3. Moderating effect of prior knowledge

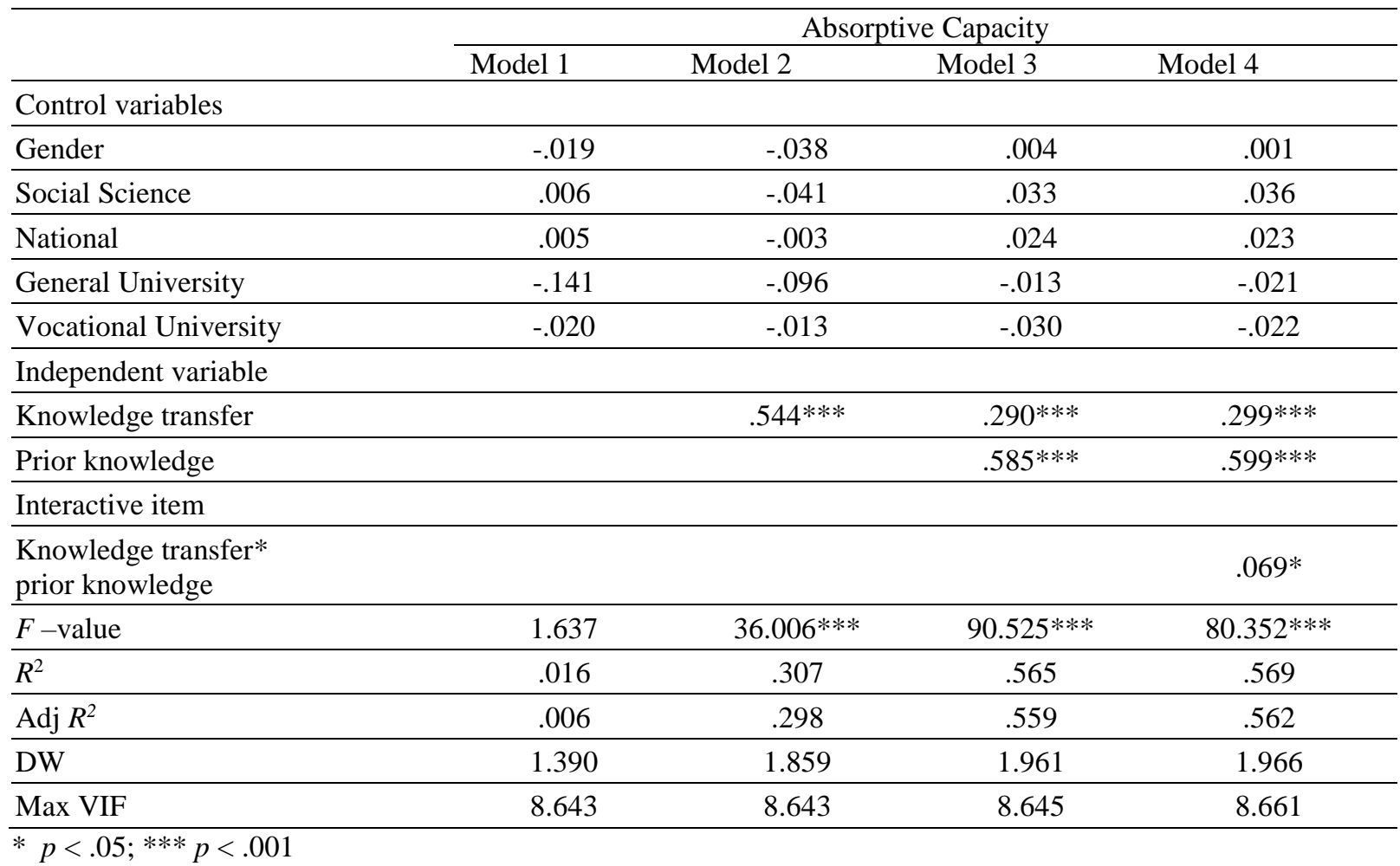

\section{Discussion}

The findings of this study show that the acquisition of knowledge sources has a significant impact on student absorptive capacity and student learning outcomes, indicating that the teacher's teaching of tacit and explicit knowledge in the classroom will help develop the absorptive capacity of knowledge and reflect on the learning outcome. This is in agreement with the research of Tho (2017) that acquired knowledge is a determinant of knowledge transfer. This result shows that teacher, as a knowledge transmitter, plays an absolutely important role in the student learning process (Sadler, 2010). In addition to imparting the knowledge of professional courses, teachers also need to communicate and interact with students in depth. This serves to provide students with a learning path through the tacit knowledge externalization, to enhance the ability to use tacit and explicit knowledge as their own, and to gradually consolidate the students' ability base. The research results integrate the fragmented literature of knowledge management into a holistic view and develop a framework for higher education training, which is in congruence with knowledge conversion theory and the research of Cho et al. (2013), Cho and Korte (2014) and Yeoh (2009). The application of knowledge transfer theory to the cultivation and establishment of students' abilities is significant. The interpretation results also confirm that the relevant theories applied to the discussion of enterprise management apply to higher education research, the application of this enrichment theory and the feasibility of cross-domain.

Furthermore, higher education institutions adopt a customer-oriented model of marketing concepts to construct a student orientation culture that is part of the college, so that both administrative and academic units within the college provide student-oriented learning services to meet the needs of students, thereby improving students' desire for learning. Environment and curriculum teaching content make students willing to invest in learning and enhance their capabilities. As found in the study, student orientation only 
had a positive effect on student absorptive capacity, but not on student learning outcomes. This meant that students could use their learning resources relatively when they felt the goodwill of the college and their commitment to provide resources. With services, this phenomenon may not be demonstrated in the course of teaching. However, after class time, students' willingness to study independently can be improved and their ability to absorb knowledge can be further enhanced. The results of this study are also the same as those described by Cho (2012) and Blömeke (2012). Student orientation enables teachers to adopt effective teaching strategies and provide students with the necessary knowledge content and interactive feedback to cultivate the basis of student absorptive capacity.

However, the findings of this study show that student orientation is irrelevant to student learning outcomes, and this result is somewhat different from previous literature inferences (Cho, 2012). The reason for this may be that the learning-oriented system is a guideline, a normative and marketing concept promoted by higher education institutions. This culture requires time to subtly spread to all administrative units and members of the academic unit within the organization, which is indirectly reflected in student learning. In addition, the studies of Hollins $\operatorname{Jr}$ (2009), Pesch et al. (2008) consider the student retention rate as the target of improvement, rather than the student learning outcome as the item to be discussed. The difference in the dependent variables may be related to insignificant factors.

This study deduces that student absorptive capacity and student learning outcomes have a positive effect, but the results show that there is no correlation between the two. The reason for this may be that student absorptive capacity is also a part of student learning outcomes. There is no correlation between the two, and student absorptive capacity does not have an effect on the learning outcome. However, this research inference differs from that of Sadler (2010). He believes that the development of student ability is a complicate and dynamic process involving the quality of a great number of student coursework, the absorption of tacit knowledge and know-how and the acquisition of teachers. The feedback (Sadler, 2009) and learning quality of professional knowledge are shaped by a number of factors that shape students' abilities. Kibbe (2015) arrived at similar results that following programme participation students significantly improved in terms of amount learned in each knowledge dimension and in terms of integration of the knowledge dimensions. It can be seen that there is a loop inference between student absorptive capacity and student learning outcomes in terms of tautology. Exactly what the causes and effects are is yet to be verified, and the contribution of this study is to verify the irrelevance between learned absorptive capacity and student learning outcomes. This can provide future researchers from different angles to think about the relationship between the two.

This study found that the prior knowledge of students will positively moderate with the relationship between teacher's knowledge transfer and student absorptive capacity. The results are the same as those of Franck et al. (2008), Jenkins et al. (2003) and Mishra and Yadav (2006). In entering the learning situation, a proper knowledge base is a must to understand and digest the concepts and viewpoints put forward by teachers in the course. Consistent with the findings of previous research (e.g., Struyven et al., 2010), students who owned more prior knowledge in the experiment for their own practice demonstrate reflective practices, make critical judgements, formulate terms or suggest amendments to skill and capacity in the way they have been accumulated as straightforward as might be expected. However, Seery (2009) pointed out that while discussing prior knowledge, gender and disciplinary differences should be added because female students are better at using reading skills, while male students have better performance in scientific knowledge. Therefore, if different background factors can be added to discuss the influence of prior knowledge in the future, different results may be produced. 


\section{Practical implications}

The path coefficients in the structural model validation of this study prove that teachers' knowledge transfer possesses a higher student absorptive capacity and learning outcome than other path variables, and also represent that teachers' knowledge transfer has a vital function in student learning. Teachers do not only need to provide students with representational knowledge in specialized courses, but also provide indepth and diverse counseling services. However, students' needs for learning change over time, and students respond to their needs in teaching assessment. It can only serve as a reference for teachers in the adjustment of future teaching styles. It has little effect on the professional growth of teachers. This study suggests that college teachers represent the most important window of interaction between colleges and students. If colleges can provide support measures for teacher professional growth, teachers can strengthen their professional skills in addition to teaching, research, and service counseling. The system can be assisted, and the benefits can be achieved. For example, its support system includes teaching development centers for processing and subsidizing teacher professional studies, and the Research and Design (R\&D) office can provide on-campus teacher research cooperation platforms to enhance the guidance function for students.

Furthermore, the study found that student orientation had a significant impact on student absorptive capacity, implying that the college should strengthen the student orientation culture and related actions, so that students feel the sincerity of the college. Colleges will gain internal and external benefits while strengthening student orientation. In the internal interest section, students perceive that the college is willing to invest in college resources and counselling services. They will actively use hardware facilities and an environment conducive to learning, cultivate students' motivation and attitudes for self-learning, and increase students' absorptive preparation before class. In the external interest section, the concept of marketing will be applied to the daily tasks of the college's internal administrative units and academic units. This will create a student's reputation and forge the college's long-term brand equity and reputation, while further enhancing the positive relationship of external stakeholders to the college. Therefore, this study suggests that the student orientation culture should be implemented by the upper and lower layers. The principal should work out the vision the college members wish to achieve. The head of the department is assigned to inculcate its ideas in the frontline members, and the executives of each unit control their implementation. The student satisfaction survey was conducted for a period of time, and the implementation and decision-making process of the task was adjusted again.

The study's results indicate that the prior knowledge of students will enhance the positive relationship between teachers' knowledge transfer and student absorptive capacity. When the student's knowledge foundation is more stable, students will better understand the teacher's curriculum knowledge. It reinforces knowledge connotation and knowledge concepts, thus strengthening students' cultivation of the absorptive capacity of knowledge. However, in the same class, each student's prior knowledge is different. Teachers' knowledge transfer and students' education experience are not the same, so the teaching practice should consider the homogeneity of the prior knowledge of students. Therefore, this study proposes that the course graded shunt system is an outpost to identify student's prior knowledge, obtain classification results from the course classification and distribution, and provide a variety of information to class instructors or course tutors at the beginning of professional courses. Firstly, the tutors of the class have performed their service, hoping to achieve a homogeneity of knowledge base among the students. At the same time, they can also achieve the effect of gathering together. The students can put forward their own opinions in the discussion of the tasks of the college, instead of doing nothing and simply making the students feel indifferent. 


\section{Directions for future research}

This study has made its contribution to the theory of knowledge transfer, student orientation and student learning outcomes. However, there are still some limitations that should be further explored by future researchers to compensate for theoretical deficiencies. First, in the past, knowledge transfer has achieved a considerable development in business management. However, less attention is paid to the relationship among teachers' knowledge transfer, absorptive capacity and learning outcomes in the context of higher education. Although this study constructed its absorptive capacity and learning outcome prioritization (teachers' knowledge transfer and learning orientation) using the knowledge transfer theory, its research results also provide important findings for learning theories. However, there are still other theories that are applicable to explain how to enhance students' learning ability and effectiveness, such as the self-adjustment theory, social cognitive theory and demand hierarchy theory. Therefore, studies in the future are recommended to follow different theoretical models to construct relevant knowledge source aspects that affect student learning outcomes.

In addition, this study asks students to remember their academic performance as academic performance indicators, mainly because the actual academic performance is not easy to obtain due to personal privacy. In the future, if we can collect practical academic achievements of students under the consideration of research ethics, we may be able to better understand the relationship between the source of knowledge and the ability to learn. Third, due to time and space constraints, there were only 16 sampling colleges in this study. There were 801 valid questionnaires and the study area could not be differentiated. Scholars believe that gender is also one important factor affecting students' establishment of prior knowledge. It is suggested that in addition to expanding sample size to improve research representativeness, it is also possible to conduct multi-group discussions or comparisons in order to propose pluralistic and indepth policies for higher education.

\section{References}

Aiken, L. S., West, S. G., \& Reno, R. R. (1991). Multiple regression: Testing and interpreting interactions. Newbury Park, CA: Sage.

Amadieu, F., Tricot, A., \& Mariné, C. (2009). Prior knowledge in learning from a non-linear electronic document: Disorientation and coherence of the reading sequences. Computers in Human Behavior, 25, 381-388. doi: 10.1016/j.chb.2008.12.017

Amyx, D. A., Bristow, D. N., \& Luehlfing, M. S. (2005). A cross-cultural comparison of values and gender among university students. Academy of Educational Leadership Journal, 9, 131.

Bagozzi, R. P., \& Yi, Y. (1988). On the evaluation of structural equation models. Journal of the Academy of Marketing Science, 16, 74-94. doi: 10.1007/BF02723327

Blömeke, S. (2012). Does greater teacher knowledge lead to student orientation? The relationship between teacher knowledge and teacher beliefs. In J. König (Ed.), Teachers'Pedagogical Beliefs (pp. 15-35). Retrieved from https://play.google.com/books/readerid=MYyRBYGIYTQC\&printsec=frontcover\&output=reader\&authuse $\mathrm{r}=0 \& \mathrm{hl}=\mathrm{en} \& \mathrm{pg}=\mathrm{GBS} . \mathrm{PA} 3$

Bristow, D. N., \& Amyx, D. (2006). The satisfaction with cultural diversity in the educational environment scale (SCDEE): Development and testing. Review of Business Research, 6, 28-38.

Cadiz, D., Sawyer, J. E., \& Griffith, T. L. (2009). Developing and validating field measurement scales for absorptive capacity and experienced community of practice. Educational and Psychological Measurement, 69, 10351058. https://doi.org/ 10.1177/0013164409344494

Canham, M., \& Hegarty, M. (2010). Effects of knowledge and display design on comprehension of complex graphics. Learning and instruction, 20, 155-166. doi: 10.1016/j.learninstruc.2009.02.014

Capron, L. (1999). The long-term performance of horizontal acquisitions. Strategic Management Journal, 20, 9871018. https://doi.org/10.1002/(SICI)1097-02 66 (199911)20:11<987::AID-SMJ61>3.0.CO;2-B 
Chen, S. W., Wang, H. H., Wei, C. F., Fwu, B. J., \& Hwang, K. K. (2009). Taiwanese students' self-attributions for two types of achievement goals. The Journal of Social Psychology, 149, 179-194. doi: 10.3200/SOCP.149.2.179-194

Cho, D., Eum, W. S. J., \& Lee, K. H. (2013). The impact of organizational learning capacity from the sociocognitive perspective on organizational commitment. Asia Pacific Education Review, 14, 511-522. doi: $10.1007 / \mathrm{s} 12564-013-9282-9$

Cho, M. H. (2012). Online student orientation in higher education: A developmental study. Educational Technology Research and Development, 60, 1051-1069. doi: 10.1007/s11423-012-9271-4

Cho, T., \& Korte, R. (2014). Managing knowledge performance: Testing the components of a knowledge management system on organizational performance. Asia Pacific Education Review, 15, 313-327. doi: 10.1007/s12564014-9333-X

Cohen, W. M., \& Levinthal, D. A. (1990). Absorptive capacity: A new perspective on learning and innovation. Administrative Science Quarterly, 35, 128-152. doi: 10.2307/2393553

Dalkir, K., \& Beaulieu, M. (2017). Knowledge management in theory and practice. London: MIT press.

Desai, S., Damewood, E., \& Jones, R. (2001). Be a good teacher and be seen as a good teacher. Journal of Marketing Education, 23, 136-144.

Deshpande, R., \& Webster Jr, F. E. (1989). Organizational culture and marketing: defining the research agenda. The Journal of Marketing, 53, 3-15. doi: 10.1177/002224298905300102

Ding, L., Wei, X., \& Mollohan, K. (2016). Does higher education improve student scientific reasoning skills? International Journal of Science and Mathematics Education, 14, 619-634. doi: 10.1007/s10763-014-9597-y

Drucker, P. F. (1999). Knowledge-worker productivity: The biggest challenge. California Management Review, 41, 79-94. doi: $10.2307 / 41165987$

Fabrizio, K. R. (2009). Absorptive capacity and the search for innovation. Research Policy, 38, 255-267. doi: 10.1016/j.respol.2008.10.023

Hair, J., Black, W., Babin, B., Anderson, R., \& Tatham, R. (2010). SEM: An introduction. Multivariate data analysis: A global perspective (7th ed.). New Jersey: Pearson-Prentice Hall.

Hau, Y. S., Kim, B., Lee, H., \& Kim, Y. G. (2013). The effects of individual motivations and social capital on employees' tacit and explicit knowledge sharing intentions. International Journal of Information Management, 33, 356-366. doi: 10.1016/j.ijinfomgt.2012.10.009

Hennemann, S., \& Liefner, I. (2010). Employability of German geography graduates: The mismatch between knowledge acquired and competences required. Journal of Geography in Higher Education, 34, 215-230. doi: $10.1080 / 03098260903227400$

Hollins Jr, T. N. (2009). Examining the impact of a comprehensive approach to student orientation. Inquiry, 14, 1527.

Jenkins, J. R., Fuchs, L. S., Van Den Broek, P., Espin, C., \& Deno, S. L. (2003). Sources of individual differences in reading comprehension and reading fluency. Journal of Educational Psychology, 95, 719. doi: 10.1037/00220663.95.4.719

Jöreskog, K. G., \& Sörbom, D. (1993). LISREL 8: Structural equation modeling with the SIMPLIS command language. Mooresville, IL: Scientific Software

Kertechian, S. K. (2018). Conscientiousness as a key to success for academic achievement among French university students enrolled in management studies. International Journal of Management Education, 16, 154-165. doi: 10.1016/j.ijme.2018.02.003

Kibbe, A. (2015). Evaluating Environmental Knowledge Dimension Convergence to Assess Educational Programme Effectiveness. International Journal of Science Education, 37, 684-702. doi: 10.1080/09500693.2015. 1010628

Koris, R., \& Nokelainen, P. (2015). The student-customer orientation questionnaire (SCOQ) application of customer metaphor to higher education. International Journal of Educational Management, 29, 115-138. doi: 10.1108/IJEM-10-2013-0152

Little, T. D., Cunningham, W. A., Shahar, G., \& Widaman, K. F. (2002). To parcel or not to parcel: Exploring the question, weighing the merits. Structural Equation Modeling, 9, 151-173. doi: 10.1207/S15328007SEM 0902_1

Machlup, F. (1962). The production and distribution of knowledge in the United States (Vol. 278). Princeton, NJ: Princeton University Press.

Mathai, S., \& Ramadas, J. (2009). Visuals and visualisation of human body systems. International Journal of Science Education, 31, 439-458. doi: 10.1080/09500690802595821 
Mishra, P., \& Yadav, A. (2006). Using hypermedia for learning complex concepts in chemistry: A qualitative study on the relationship between prior knowledge, beliefs, and motivation. Education and Information Technologies, 11, 33-69. doi: 10.1007/s10639-005-5712-6

Müller-Kalthoff, T., \& Möller, J. (2003). The effects of graphical overviews, prior knowledge, and self-concept on hypertext disorientation and learning achievement. Journal of Educational Multimedia and Hypermedia, 12, 117-134.

Murphy, E., \& Rodríguez-Manzanares, M. A. (2009). Learner Centredness in High School Distance Learning: Teachers' Perspectives and Research Validated Principles. Australasian Journal of Educational Technology, 25, 597-610.

Narver, J. C., \& Slater, S. F. (1990). The effect of a market orientation on business profitability. The Journal of Marketing, 54, 20-35. doi: 10.1177/002224299005400403

Nieto, M., \& Quevedo, P. (2005). Absorptive capacity, technological opportunity, knowledge spillovers, and innovative effort. Technovation, 25, 1141-1157. doi: 10.1016/j.technovation.2004.05.001

Nonaka, I., \& Takeuchi, H. (1995). The knowledge-creating company: How Japanese companies create the dynamics of innovation. New York: Oxford University Press.

Nonaka, I., \& Von Krogh, G. (2009). Perspective-Tacit knowledge and knowledge conversion: Controversy and advancement in organizational knowledge creation theory. Organization Science, 20, 635-652. doi: 10.1287/orsc. 1080.0412

Nor, M. N. M., Nor, N. M., Daud, N. M., \& Kamaruddin, B. H. (2012). Determining the moderating impact of lecturer support on the relationship between students' absorptive capacity, motivation and knowledge transfer. Advances in Natural and Applied Sciences, 6, 1238-1245.

Olssen, M., \& Peters, M. A. (2005). Neoliberalism, higher education and the knowledge economy: From the free market to knowledge capitalism. Journal of Education Policy, 20, 313-345. doi: $10.1080 / 02680930500108718$

Pesch, M., Calhoun, R., Schneider, K., \& Bristow, D. (2008). The student orientation of a college of business: An empirical look from the students' perspective. The Marketing Management Journal, 18, 100-108.

Pike, G. R., Kuh, G. D., McCormick, A. C., Ethington, C. A., \& Smart, J. C. (2011). If and when money matters: The relationships among educational expenditures, student engagement and students' learning outcomes. Research in Higher Education, 52, 81-106. doi: 10.1007/s11162-010-9183-2

Polanyi, M. (1962). Tacit knowing: Its bearing on some problems of philosophy. Reviews of Modern Physics, $34,601$.

Roth, R. M. (2006). Introduction to coding theory. New York: Cambridge University Press.

Sadler, D. R. (2010). Beyond feedback: Developing student capability in complex appraisal. Assessment \& Evaluation in Higher Education, 35, 535-550. doi: 10.1080/02602930903541015

Schein, E. (1992). Organisational culture and leadership. San Francisco: Jossey-Bass Inc.

Seery, M. K. (2009). The role of prior knowledge and student aptitude in undergraduate performance in chemistry: a correlation-prediction study. Chemistry Education Research and Practice, 10, 227-232. doi: 10.1039/B914502H

Silva, A. P., Lourtie, P., \& Aires, L. (2013). Employability in online higher education: A case study. The International Review of Research in Open and Distributed Learning, 14, 106-125. doi: 10.19173/irrodl.v14i1.1262

Simcock, G., \& DeLoache, J. (2006). Get the picture? The effects of iconicity on toddlers' reenactment from picture books. Developmental Psychology, 42, 1352. doi: 10.1037/0012-1649.42.6.1352

Struyven, K., Dochy, F., \& Janssens, S. (2010). 'Teach as you preach': the effects of student-centred versus lecturebased teaching on student teachers' approaches to teaching. European Journal of Teacher Education, 33, 4364. doi: 10.1080/02619760903457818

Sturm, H., \& Bogner, F. X. (2008). Student-oriented versus teacher-centred: The effect of learning at workstations about birds and bird flight on cognitive achievement and motivation. International Journal of Science Education, 30, 941-959. doi: 10.1080/09500690701313995

Teigland, R., \& Wasko, M. (2009). Knowledge transfer in MNCs: Examining how intrinsic motivations and knowledge sourcing impact individual centrality and performance. Journal of International Management, 15, 15-31. doi: 10.1016/j.intman.2008.02.001

Tho, N. D. (2017). Knowledge transfer from business schools to business organizations: the roles absorptive capacity, learning motivation, acquired knowledge and job autonomy. Journal of Knowledge Management, 21, 12401253. doi: $10.1108 / \mathrm{JKM}-08-2016-0349$

Von Krogh, G., \& Roos, J. (1994). Knowledge in organizations, knowledge transfer and cooperative strategies. International Business Review, 3, 331-335. doi: 10.1016/0969-5931(94)90026-4 
Wang, C. L., \& Ahmed, P. K. (2007). Dynamic capabilities: A review and research agenda. International journal of management reviews, 9, 31-51. doi: 10.1111/j.1468-2370.2007.00201.x

Yeoh, P. L. (2009). Realized and potential absorptive capacity: Understanding their antecedents and performance in the sourcing context. Journal of Marketing Theory and Practice, 17, 21-36. doi: 10.2753/MTP10696679170102

Zaheer, A., \& Bell, G. G. (2005). Benefiting from network position: firm capabilities, structural holes, and performance. Strategic Management Journal, 26, 809-825. doi: 10.1002/smj.482

Zahra, S. A., \& George, G. (2002). Absorptive capacity: A review, reconceptualization, and extension. Academy of Management Review, 27, 185-203. doi: 10.5465/amr.2002.6587995

Zhou, S., Siu, F., \& Wang, M. (2010). Effects of social tie content on knowledge transfer. Journal of Knowledge Management, 14, 449-463. doi: 10.1108/1367327101105 0157 